\title{
Antibacterial properties of a self-cured acrylic resin composed of a polymer coated with a silver-containing organic composite antibacterial agent
}

\author{
Takashi KIRIYAMA, Kenjiro KUROKI, Keisuke SASAKI, Masahumi TOMINO, Masaki ASAKURA, Yoshiko KOMINAMI, \\ Yoshihumi TAKAHASHI and Tatsushi KAWAI \\ Department of Dental Materials Science, School of Dentistry, Aichi-Gakuin University, 1-100 Kusumoto-cho, Chikusa-ku, Nagoya 464-8650, Japan \\ Corresponding author, Takashi KIRIYAMA; E-mail: takakiri01291980@yahoo.co.jp
}

\begin{abstract}
A novel antibacterial polymer, coated with a silver-containing organic composite antibacterial agent, was dispersed in a self-cured acrylic resin. Residual viable cell count of each oral bacterial and fungal species cultivated on acrylic resin specimens containing the antibacterial polymer was significantly decreased when compared to those cultivated on specimens prepared from untreated polymer. A strong inverse correlation was found between the amount of eluted silver ions and the residual viable cell count of all species grown on the antibacterial polymer: the lower the viable cell count, the higher the amount of eluted silver ions. This clearly indicated the antibacterial activity of silver ions. As the content of organic composite antibacterial agent added to the polymer increased from $0.5 \%$ to $1.5 \%$ in $0.5 \%$ increments, amount of eluted silver ions significantly increased with each $0.5 \%$ increment to exert greater antibacterial effect.
\end{abstract}

Keywords: Bacteria, Silver ion, Antibacterial agent, Self-cured acrylic resin

\section{INTRODUCTION}

Self-cured resins are popularly and prevalently used to construct facing crowns, temporary crowns and bridges, and in the repair of acrylic resin-based dentures. There is increasing evidence that plaque easily forms on acrylic resin surfaces, which then causes a variety of oral conditions such as secondary caries, marginal periodontitis, and denture stomatitis ${ }^{1-3)}$. To maintain oral cleanliness, it is useful to endow self-cured resins with antibacterial properties.

Many research studies have focused on incorporating antibacterial agents into dental materials to render the latter antimicrobial ${ }^{4-19}$. In the present study, a novel antibacterial polymer was developed. It was constituted of two key ingredients: a silver-containing organic composite antibacterial agent and a self-curing acrylic polymer. NOVARON AG300 (Toagosei Co Ltd., Tokyo, Japan), an inorganic antibacterial agent made up of zirconium phosphate ceramics containing silver ions in the crystal structure, was dispersed in a multifunctional monomer (trimethylolpropane trimethacrylate, TMPT). After polymerization and pulverization, the self-curing acrylic polymer of Unifast III (GC Corp., Tokyo, Japan; UF III) was coated with the pulverized form of the organic composite antibacterial agent. Polymer particles of Unifast III coated with pulverized antibacterial agent were created using a polymer processing technique known as Surface Uniformity Revolutionary Fixation (SURF) technology ${ }^{20)}$. Henceforth in this paper, this material is referred to as the antibacterial polymer.

Four kinds of oral bacteria (Streptococcus mutans, Streptococcus oralis, Streptococcus gordonii, and Actinomyces naeslundii) have been shown to contribute to the initial attachment and mature architecture development of biofilms. Among microbial populations,
Candida albicans is a fungus commonly detected on acrylic resin denture surfaces ${ }^{21)}$. To examine the antimicrobial properties of the novel antibacterial polymer, these oral bacterial and fungal species were used in this study. To determine the relation between residual viable cell count and the amount of eluted silver ions, concentrations of silver ions in the suspensions of bacterial and fungal cells were also measured.

\section{MATERIALS AND METHODS}

\section{Antibacterial polymer preparation}

A self-cured acrylic resin, Unifast III (GC Corp., Tokyo, Japan), was used as the base material. An organic composite antibacterial agent was used as the antibacterial agent; its composition is shown in Table 1.

After pretreatment with alcohol solvent, Unifast III polymer surface was coated with the organic composite antibacterial agent at $0.5,1.0$, and $1.5 \mathrm{wt} \%$ of the amount of polymer using SURF technology. Figure 1 is the schematic diagram illustrating the process for antibacterial polymer preparation. Production of the organic composite antibacterial agent and coating of the Unifast III polymer surface were provided by GC Dental Products.

\section{Polymer surface observation}

Secondary electron images (SEI) were taken of the surfaces of the antibacterial polymer and untreated polymer using an electron probe microanalyzer (JXA8530FA, JEOL, Tokyo, Japan; EPMA) at an accelerating voltage of $15 \mathrm{kV}$ and a probe current of $5 \mathrm{nA}$.

Elemental analysis of cured acrylic resin composed of the antibacterial polymer

After mixing $0.5 \mathrm{~mL}$ of the monomer liquid with $1.0 \mathrm{~g}$ of 
Table 1 Composition of silver-containing organic composite antibacterial agent

\begin{tabular}{lccc}
\hline \multicolumn{1}{c}{ Ingredient } & & $\begin{array}{c}\text { Particle size } \\
\text { (average) }\end{array}$ & $\begin{array}{c}\text { Specific } \\
\text { gravity }\end{array}$ \\
\hline NOVARON & $70.0 \mathrm{wt} \%$ & $0.5 \mu \mathrm{m}$ & 2.4 \\
$\begin{array}{l}\text { Trimethylolpropane } \\
\text { trimethacrylate (TMPT) }\end{array}$ & $29.7 \mathrm{wt} \%$ & - & - \\
$\begin{array}{l}\text { Azobisisobutyronitrile } \\
\text { (AIBN) }\end{array}$ & $0.3 \mathrm{wt} \%$ & - & - \\
\hline
\end{tabular}

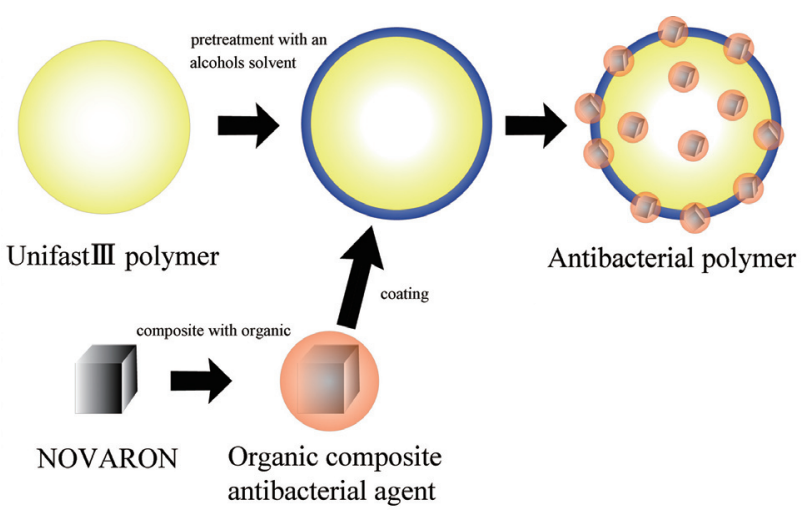

Fig. 1 Schematic diagram illustrating the process for antibacterial polymer preparation.

the antibacterial polymer, the mixture was pressed into a 24-hole plate to produce discoid specimens of $18 \mathrm{~mm}$ diameter. One surface of each specimen was polished with \#2000 Emery paper, followed by mirror-polishing with $0.3-\mu \mathrm{m}$ alumina powder and ultrasonic cleaning. Elemental analysis by EPMA was carried out on this polished and cleaned surface of each specimen to confirm the presence of the antibacterial agent.

Silver ions included in NOVARON could not be detected because of low concentration levels. Therefore, elemental analysis was performed to detect zirconium: zirconium phosphate was used as a carrier of silver ions in NOVARON. Backscattered electron images (BEI) and element distribution maps of zirconium were obtained by EPMA at an accelerating voltage of $15 \mathrm{kV}$ and a probe current of $50 \mathrm{nA}$. Electron beam diameter was $1 \mu \mathrm{m}$ on the specimen surface. Scans were performed with $1-\mu \mathrm{m}$ step size, and measurement time at each point was $10 \mathrm{~min}$.

Assessment of antimicrobial effects of cured acrylic resin composed of the antibacterial polymer

Four types of oral bacteria contribute to the initial formation of biofilms on tooth and acrylic resin surfaces: Streptococcus mutans (NCTC 10449; S. mutans), Streptococcus oralis (ATCC 9811; S. oralis), Streptococcus gordonii (bL-1; S. gordonii) and Actinomyces naeslundii
Table 2 Details of fluid and agar media types used for antimicrobial effect assessment

\begin{tabular}{ccc}
\hline Bacterium/Fungus & Fluid-medium & Agar-medium \\
\hline S. mutans & $\begin{array}{c}\text { Trypticase Soy } \\
\text { broth }\end{array}$ & $\begin{array}{c}\text { Trypticase Soy } \\
\text { agar }\end{array}$ \\
S. oralis & $\begin{array}{c}\text { Heart Infusion } \\
\text { broth }\end{array}$ & $\begin{array}{c}\text { Heart Infusion } \\
\text { agar }\end{array}$ \\
S. gordonii & $\begin{array}{c}\text { Heart Infusion } \\
\text { broth }\end{array}$ & Heart Infusion \\
A. naeslundii & Todd Hewitt & agar \\
& broth & Heart Infusion \\
C. albicans & Todd Hewitt & agar \\
& broth & CHROMagar \\
\end{tabular}

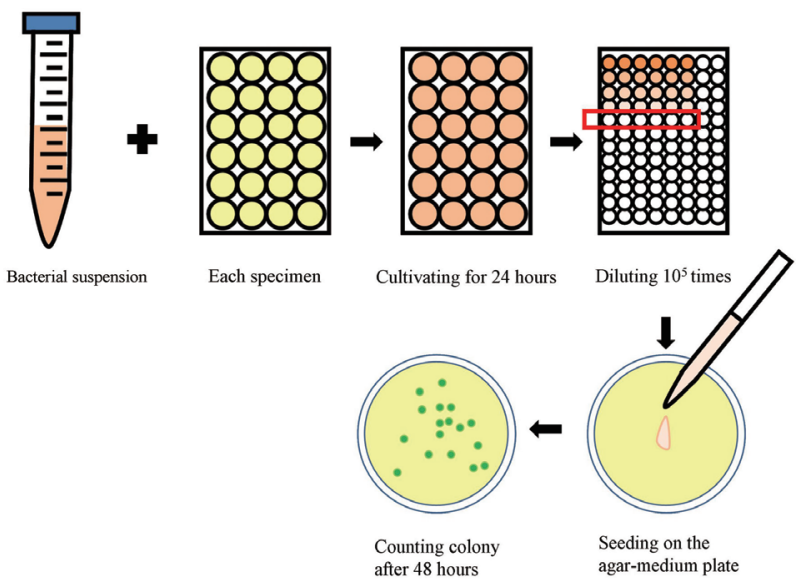

Fig. 2 Schematic diagram illustrating the steps of assessing antimicrobial effects on bacteria and fungus.

(ATCC 12104; A. naeslandii) ${ }^{21)}$. The fungus, Candida albicans (A9; C. albicans), causes denture stomatitis. These five types of oral bacterial and fungal species were thus selected to test the antimicrobial effects of antibacterial polymer in this study.

Discoid specimens of cured acrylic resin were prepared for this assessment in the same manner as that done for elemental analysis. For each bacterial or fungal species, 12 specimens were prepared. Ethylene oxide gas was used to sterilize all prepared specimens.

Table 2 lists the fluid and agar media types used in this study to grow the bacteria and fungus. Bacteria and fungus were grown in $50 \mathrm{~mL}$ of their respective fluid media at $37^{\circ} \mathrm{C}$ for $24 \mathrm{~h}$. A $500-\mu \mathrm{L}$ suspension of each bacterial or fungal species was added to each specimen in a 24 -well plate and cultured in an incubator at $37^{\circ} \mathrm{C}$ for $24 \mathrm{~h}$. Resulting cell suspensions were extracted and diluted in physiological saline by a factor of $10^{5}$ times. A $50-\mu \mathrm{L}$ diluted bacterial or fungal 
suspension was inoculated in a plate of agar medium, and the colony count of each bacterial and fungal species formed on the agar plate was determined after 48-h incubation at $37^{\circ} \mathrm{C}$ (Fig. 2).

Quantitative analysis of silver ions eluted from cured acrylic resin composed of the antibacterial polymer

A $300-\mu \mathrm{L}$ volume of bacterial or fungal suspension was diluted with $1 \%$ nitric acid to obtain a $50-\mathrm{mL}$ solution. For each bacterial and fungal species, 12 cured acrylic resin specimens were used to determine the amount of eluted silver ions.

Silver ion concentrations were measured by inductively coupled plasma mass spectrometry (NexION
300, PerkinElmer, Waltham, MA, USA; ICP-MS) using a calibration curve method. Twelve specimens were measured for each bacterial and fungal species.

\section{Statistical analysis}

Data obtained were analyzed using the Steel-Dwass multiple comparison test. Criterion for statistical significance was $p<0.05$.

\section{RESULTS}

Polymer surface observation

Figure 3 shows the EPMA-acquired SEI of untreated polymer surface and those of antibacterial polymer
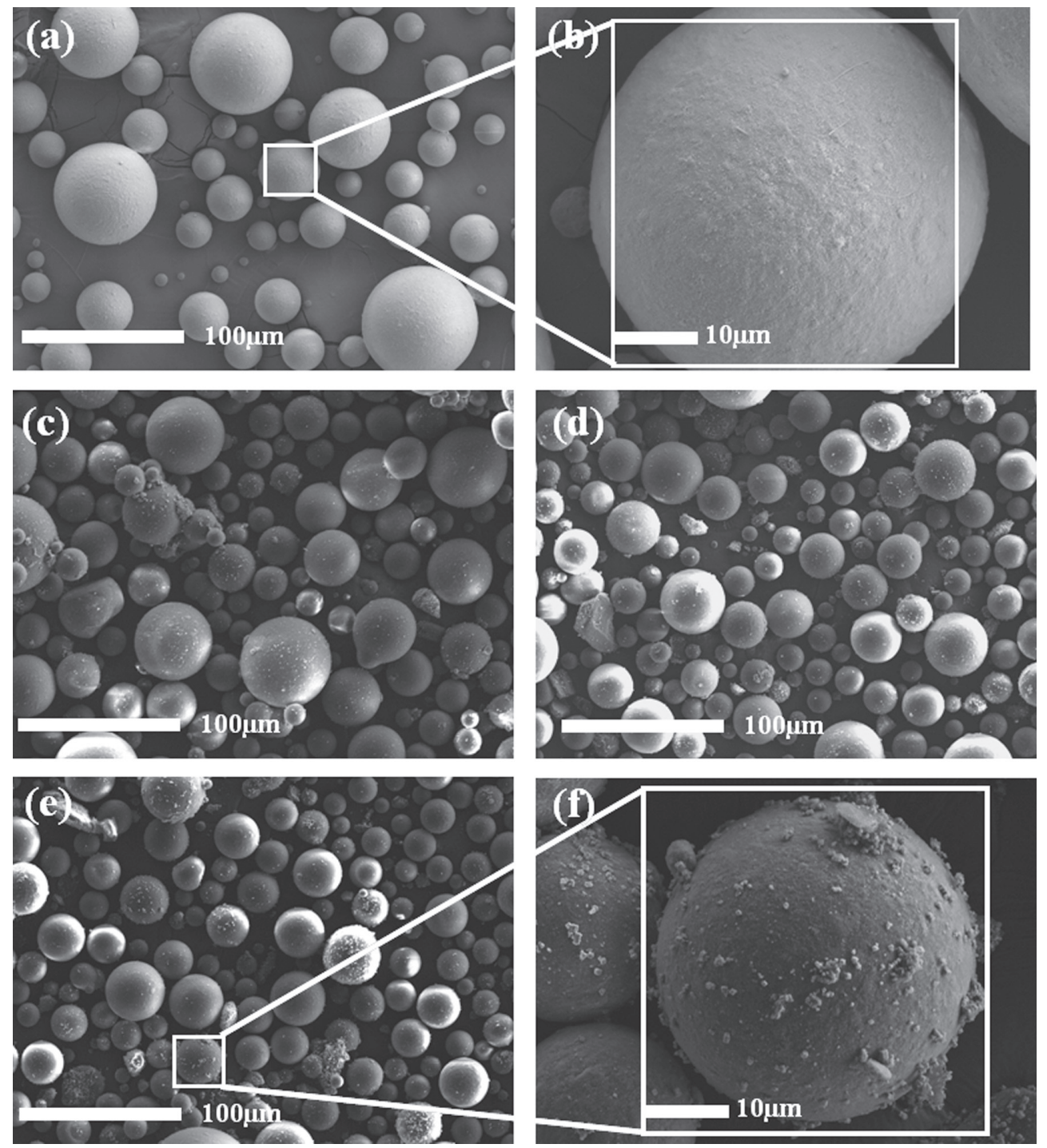

Fig. 3 SEI of polymer surface: (a) Untreated polymer; (b) Higher magnification of rectangular area in (a); (c) Polymer coated with $0.5 \%$ of organic composite antibacterial agent; (d) Polymer coated with $1.0 \%$ of organic composite antibacterial agent; (e) Polymer coated with $1.5 \%$ of organic composite antibacterial agent; and (f) Higher magnification of rectangular area in (e). 
coated with 0.5-1.5 wt\% of organic composite antibacterial agent. At a higher magnification (Fig. 3f), pulverized organic composite antibacterial agent was observed to be uniformly distributed on Unifast III polymer surface.

Elemental analysis of cured acrylic resin composed of antibacterial polymer

Figure 4 shows the BEI of cured acrylic resin specimens prepared from different amounts of organic composite antibacterial agent $(0.5-1.5 \mathrm{wt} \%)$, and the element distribution maps of zirconium on their corresponding surfaces. White particles of zirconium in the element distribution maps increased with the amount of organic composite antibacterial agent.

\section{Antimicrobial effect assessment}

Figure 5 shows the results of antimicrobial effects against five kinds of bacteria and fungus. The residual viable cell count of each type of bacterium and fungus cultured on the antibacterial polymer specimen was significantly decreased when compared to that of untreated polymer $(p<0.01)$. Moreover, the residual viable cell count of each bacterial and fungal species significantly decreased with increasing amount of organic composite antibacterial agent added to antibacterial polymer $(p<0.01)$.

Silver ions eluted from cured acrylic resin composed of antibacterial polymer

Figure 6 shows the amounts of eluted silver ions found
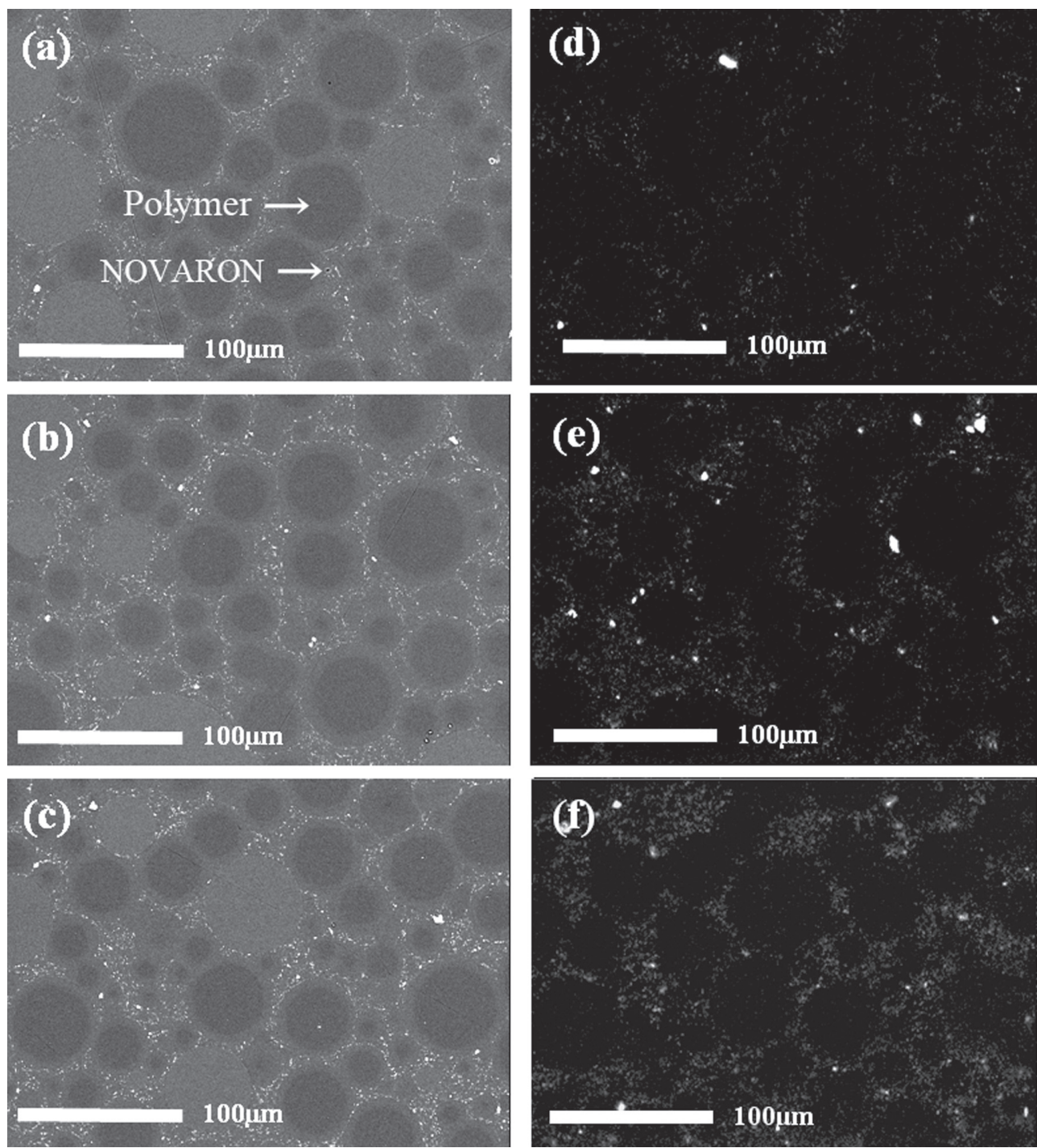

Fig. 4 BEI $(\mathrm{a}-\mathrm{c})$ and element distribution maps $(\mathrm{d}-\mathrm{f})$ of zirconium of the surface of UF III. (a) and (d): UF III coated with $0.5 \%$ of organic composite antibacterial agent; (b) and (e): UF III coated with $1.0 \%$ of organic composite antibacterial agent; and (c) and (f): UF III coated with $1.5 \%$ of organic composite antibacterial agent. 


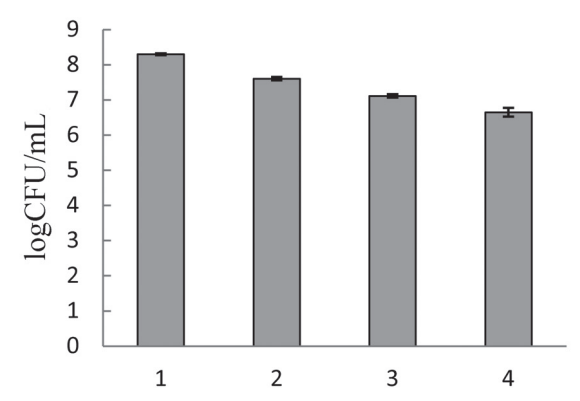

Streptococcus mutans
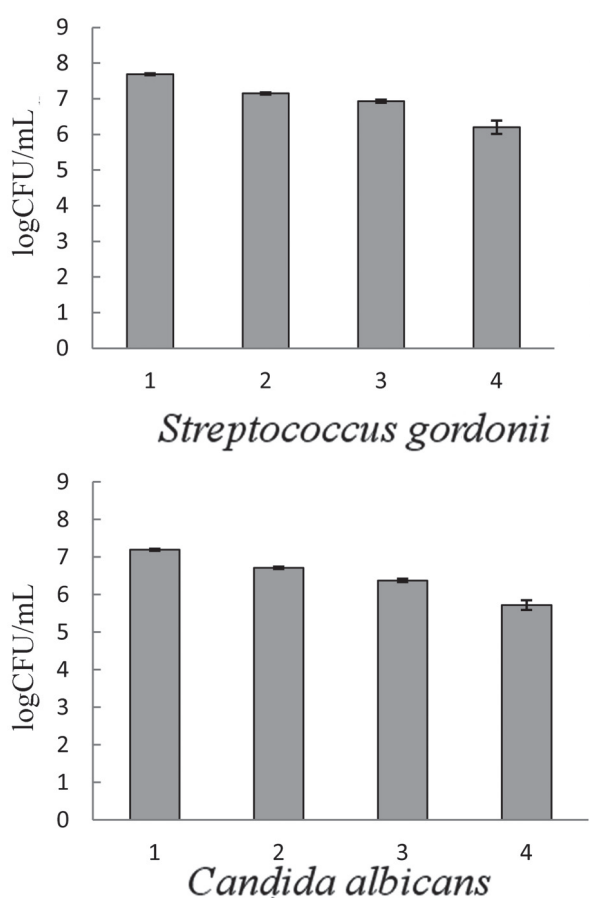

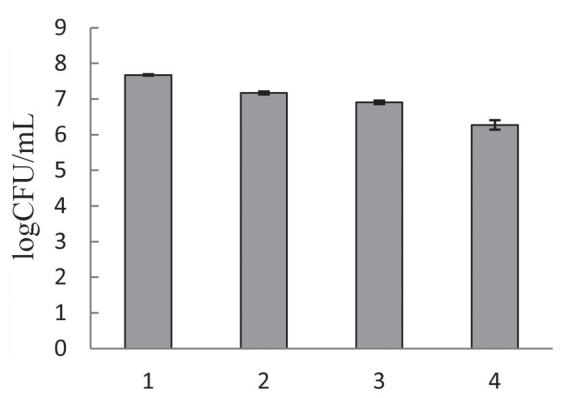

Streptococcus oralis

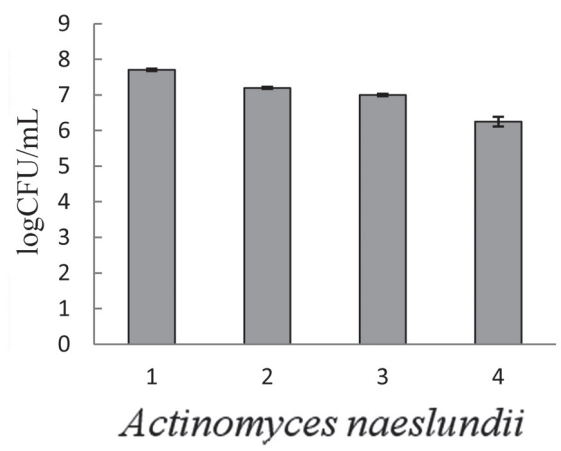

1. UFIII

2. $0.5 \%$ UFIII

3. $1.0 \%$ UFIII

4. $1.5 \%$ UFIII

Fig. 5 Quantitative results of antimicrobial effect assessment, with significant differences among Groups 1-4 $(p<0.01)$ for each type of bacterium or fungus. $0.5 \%$ UF III: UF III coated with $0.5 \%$ of organic composite antibacterial agent; $1.0 \%$ UF III: UF III coated with $1.0 \%$ of organic composite antibacterial agent; $1.5 \%$ UF III: UF III coated with $1.5 \%$ of organic composite antibacterial agent.

in five kinds of bacterial and fungal suspensions. The concentration of silver ions significantly increased with increasing amount of organic composite antibacterial agent added to antibacterial polymer $(p<0.01)$. Analysis results for the bacterial and fungal suspensions of untreated polymer were excluded because detection limit was exceeded.

\section{DISCUSSION}

Plaque, which must be controlled, is typically removed using physical means such as toothbrushes, interdental brushes, or dental floss. However, in many cases, it is impossible to completely remove plaque because of anatomical and technical reasons. The use of resin materials for dental treatments exacerbates the presence of plaque as they favor plaque formation. To counter and circumvent this problematic association between dental resins and dental plaque, many studies have focused on endowing resin-based dental materials with antibacterial properties ${ }^{4-19)}$. Currently, antibacterial agents to be incorporated into dental materials are classified into organic agents [such as quaternary ammonium salts ${ }^{5)}$, 12-methacryloyloxydodecyl-pyridinium-bromide (MDPB) ${ }^{6}$, quaternary phosphonium salts ${ }^{7}$, and bamboo extract $\left.{ }^{8}\right]$ and inorganic agents [such as silver ${ }^{4,9-18)}$ and titanium dioxide ${ }^{19)}$ ].

Evolution and development of novel antibacterial polymer Kuroki et al. ${ }^{4)}$ developed a self-cured acrylic resin 

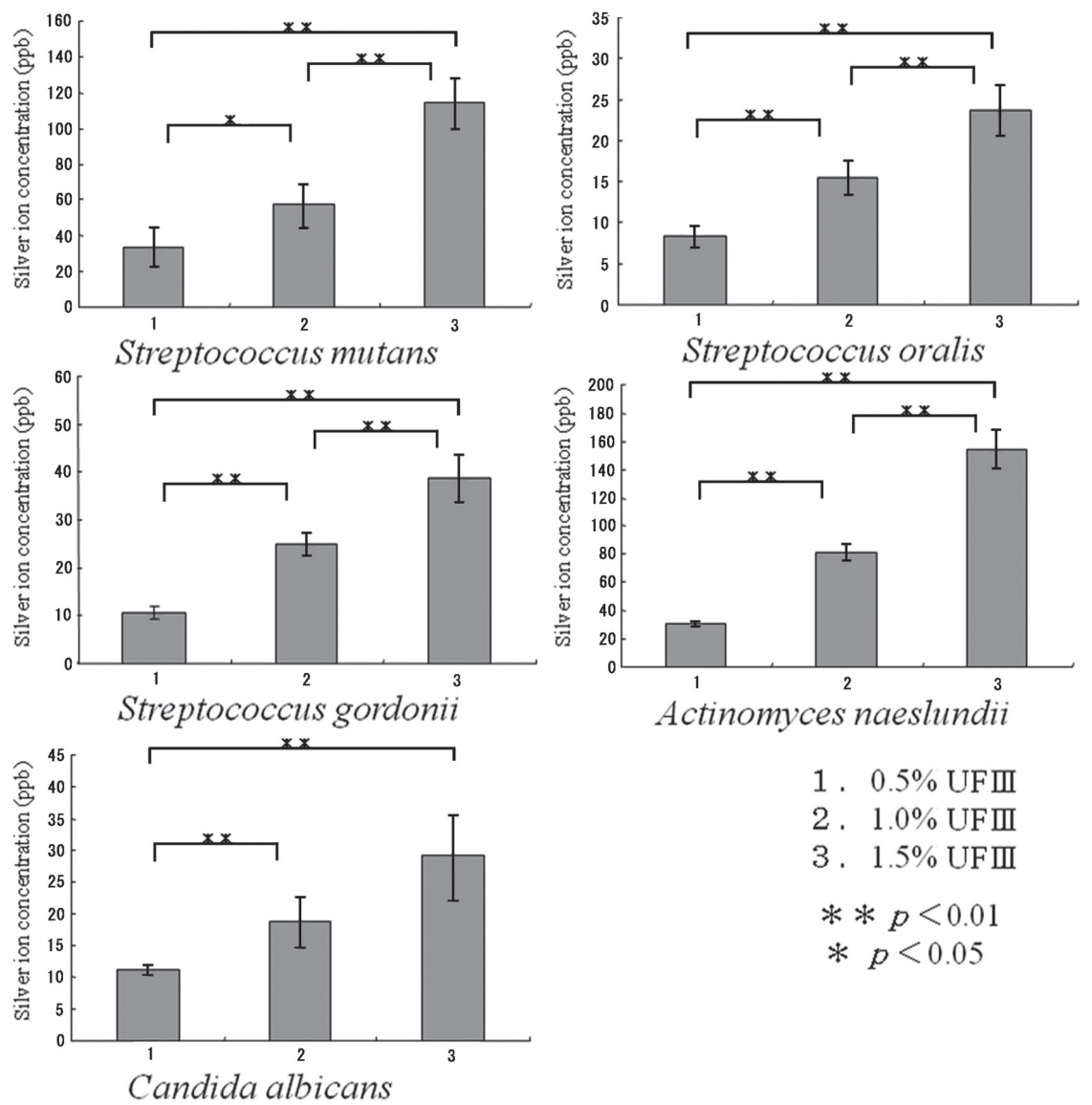

Actinomyces naeslundii

1. $0.5 \%$ UF III

2. $1.0 \%$ UF III

3. $1.5 \%$ UFIII

$* * p<0.01$

* $p<0.05$

Fig. 6 Eluted silver ions for each type of bacterium or fungus.

$0.5 \%$ UF III: UF III coated with $0.5 \%$ of organic composite antibacterial agent;

$1.0 \%$ UF III: UF III coated with $1.0 \%$ of organic composite antibacterial agent; $1.5 \%$ UF III: UF III coated with $1.5 \%$ of organic composite antibacterial agent.

constituted of polymer powder particles mixed with an acrylic monomer. The latter was added with NOVARON, which was made up of zirconium phosphate ceramics containing silver ions in the crystal structure. When this newly developed self-cured acrylic resin was tested against Streptococcus mutans, there was a significant decrease in residual viable cell count when compared to exposure to resin without antibacterial agent. However, discoloration occurred because the inorganic antibacterial agent contained metal ions.

In the preliminary experiments of this study, Kuroki et al. dispersed NOVARON in a multifunctional monomer. Polymerization and pulverization yielded an organic composite antibacterial agent (Fig. 1). This organic composite antibacterial agent also showed a pronounced antibacterial effect, but less discoloration as compared to addition of NOVARON alone. However, the preparation process was highly complicated. After a small amount of NOVARON was added to the multifunctional monomer, the antibacterial polymer was obtained by undergoing a reaction with the polymer. This meant expending significant time and effort to produce the antibacterial polymer for assessment and testing. A high-accuracy electronic balance was also required to ensure that the organic composite antibacterial agent was added at 0.1-1.0 wt\% to produce the antibacterial polymer.

To simplify the preparation process, the organic composite antibacterial agent was simply dispersed at the required quantity in the polymer. However, variations in antibacterial assessment results occurred because compact masses and deposits of organic composite antibacterial agent were randomly formed in the polymer. Specific gravity of organic composite antibacterial agent was 2.4, and the average particle size was $0.5 \mu \mathrm{m}$. Poly(methyl methacrylate), a main ingredient of self-cured acrylic resin, had a specific gravity of 1.19 and an average particle size of $40-80$ $\mu \mathrm{m}$. Vehicle vibration during transportation could have caused sedimentation of the organic composite antibacterial agent. This then caused compact masses of organic composite antibacterial agent to be randomly 
and unevenly deposited in the mixture.

In the present study, the polymer processing SURF technology ${ }^{20)}$ was applied to produce the antibacterial polymer. EMPA-acquired secondary electron images showed that this technology enabled the polymer surface to be uniformly coated with the organic composite antibacterial agent.

\section{Antimicrobial effects of novel antibacterial polymer}

In the present study, the residual viable cell counts of $S$. mutans, S. oralis, S. gordonii, A. naeslundii, and $C$. albicans were significantly decreased when tested against the organic composite antibacterial agent. Therefore, the novel antibacterial polymer exhibited antibacterial effect and inhibited biofilm formation. In terms of clinical application, the antibacterial polymer has great preventive potential against denture stomatitis.
For each type of bacterium or fungus, the residual viable cell count decreased with an increase in the amount of organic composite antibacterial agent added to Unifast III polymer. At the same time, the amount of silver ions eluted from self-cured acrylic resin increased with an increase in the amount of added organic composite antibacterial agent. These results showed that the antimicrobial effect of novel antibacterial polymer was closely and strongly related to the amount of eluted silver ions.

Figure 7 shows strong inverse correlations between the amount of eluted silver ions and residual viable cell count for five types of bacteria and fungus. For each bacterial and fungal species, the residual viable cell count decreased with an increase in the amount of eluted silver ions. These results showed that the antibacterial effect of self-cured acrylic resin composed
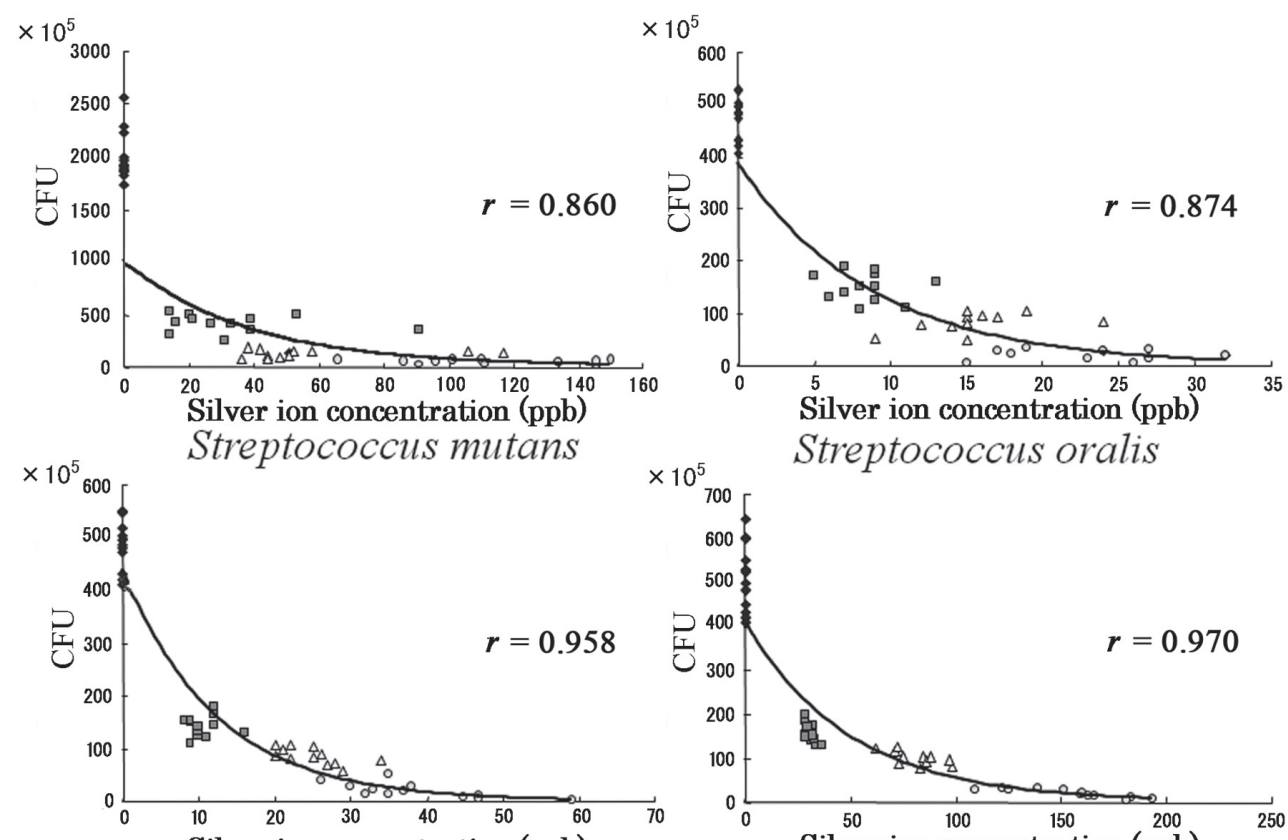

Silver ion concentration (ppb)

Streptococcus gordonii
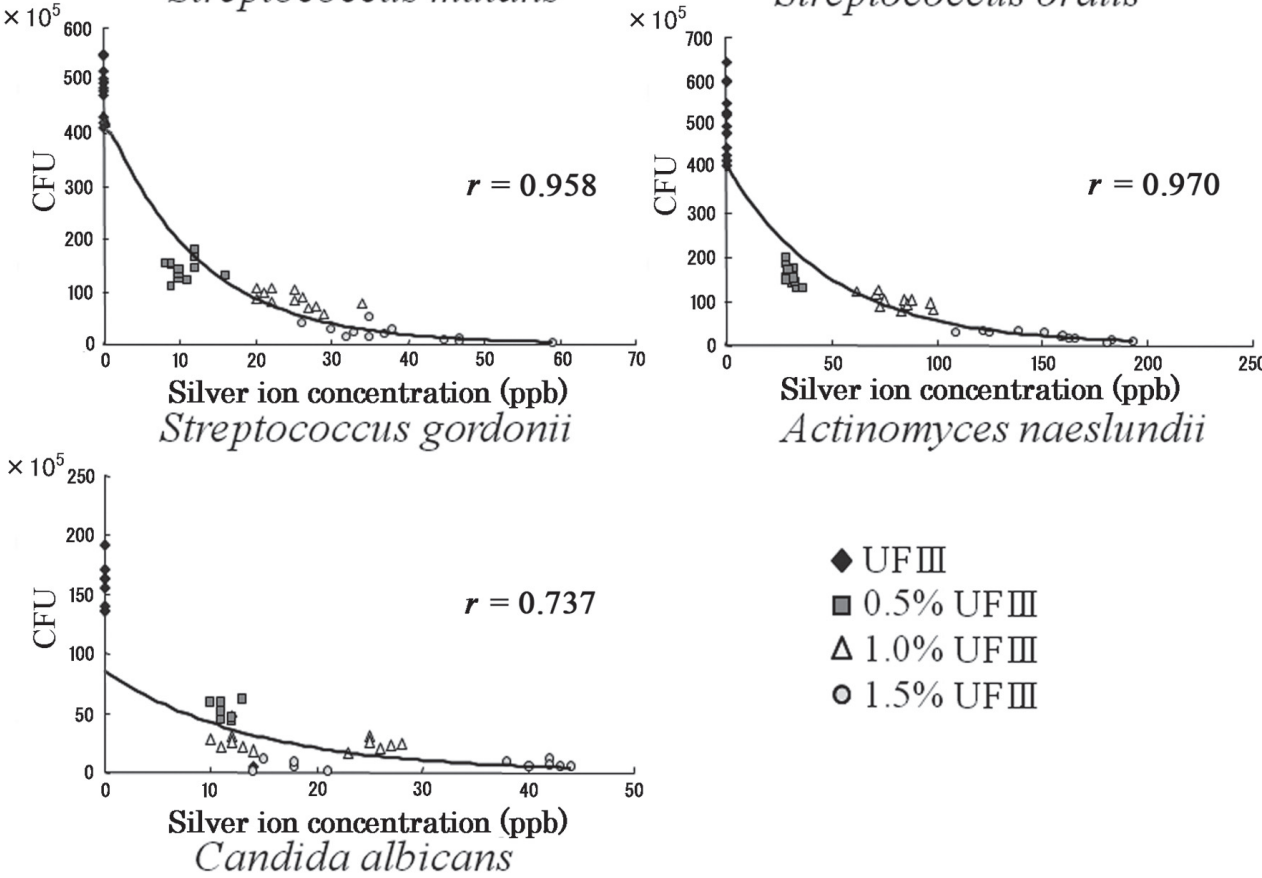

Fig. 7 Correlation diagram between CFU and eluted silver ions.

$0.5 \%$ UF III: UF III coated with $0.5 \%$ of organic composite antibacterial agent; 1.0\% UF III: UF III coated with $1.0 \%$ of organic composite antibacterial agent; $1.5 \%$ UF III: UF III coated with $1.5 \%$ of organic composite antibacterial agent. 
of organic composite antibacterial agent was influenced and determined by the amount of eluted silver ions.

\section{Mechanism of antibacterial action of silver ions}

Two theories have been put forth to explain the mechanism of antibacterial action of silver ions $\mathbf{s}^{4,9,15,22)}$. In Ionic Theory, silver ions are incorporated at intracellular level. They act as potent enzyme inhibitors which inhibit intracellular bacterial metabolism, thereby causing bacterial death ${ }^{23)}$. In "Reactive Oxygen Species" theory, silver ions act as catalysts which decompose water and generate hydroxyl radicals. Being effective in disinfection, these hydroxyl radicals cause bacterial death ${ }^{24)}$.

In bacteria, the proportion of proteins is $60-80 \%$; in fungi, it is $30-50 \%$. Amino acids responsible for enzyme activity include histidine, arginine, cysteine, glutamine, and asparagine. Among these amino acids, histidine, arginine, and cysteine have a higher affinity for silver ions as their protein content is approximately $61 \%^{23)}$. For histidine and arginine, $-\mathrm{NH}$ groups are the terminal group of the molecular structure and they react with silver ions. For cysteine, - SH groups are the terminal group which are strongly reactive with silver ions ${ }^{23)}$.

\section{Limitations of present study and avenues for future research}

It was difficult to compare the antibacterial activity results among the bacterial and fungal species tested in this study. The concentrations of bacterial and fungal suspensions were not standardized in the present study because five kinds of bacteria and one kind of fungus were grown in different types of fluid medium. In future research, the influence of growth medium for bacteria and fungi should be examined.

Nonetheless, this study provided sufficient evidence to show that self-cured acrylic resin prepared from the antibacterial polymer exhibited antimicrobial effects against four kinds of bacteria and one kind of fungus. However, antimicrobial effects differed among the species. In Fig. 7, correlation coefficient for C. albicans was lower than those of the other four bacteria. The proportion of proteins is lower in fungus than in bacteria. Therefore, compared with bacteria, fungus has a lower amount of amino acids to react with silver ions. It was also probable that the cell components and microstructure of microorganisms caused the difference in antimicrobial effects. This is another avenue for further investigation in future research.

As silver ions eluted from the self-cured acrylic resin containing the antibacterial polymer to exert antibacterial effect, there emerged two concerns to be addressed in future research: discoloration of the acrylic resin and the effect on the latter's mechanical properties.

\section{CONCLUSIONS}

Within the limitations of the present study, the following conclusions were drawn:

1. By developing an antibacterial polymer which contained silver-based NOVORON, NOVARON was able to be dispersed in self-cured acrylic resin without causing severe discoloration.

2. Residual viable cell counts of all bacterial and fungal species tested against the antibacterial polymer were significantly decreased when compared to those exposed to untreated polymer.

3. Amount of eluted silver ions significantly increased with each $0.5 \%$ incremental increase in the amount of added organic composite antibacterial agent.

4. There was a strong correlation between the amount of eluted silver ions and residual viable cell count.

\section{ACKNOLWEDGMENTS}

The authors wish to thank GC Corp. for generously providing the organic composite antibacterial agent and antibacterial polymer used in this study. We also wish to thank PerkinElmer Japan Co. Ltd. for their kind assistance in the quantitative analysis of eluted silver ions. We are grateful to Prof. Yoshimura for his kind advice on this study. This study was supported in part by the Strategic Research AGU-Platform Formation (2008-2012).

\section{REFERENCES}

1) Murakami H, Asai A, Matsui T, Nakamura K, Sakai H, Ida S, Inukai Y, Kimura K, Noguchi T, Ito Y. Microbiological findings of resin temporary crowns and bridges. J Jpn Prosthodont Soc 1996; 40 (Special issue): 85.

2) Darveau RP, Tanner A, Page RC. The microbial challenge in periodontitis. Periodontology 2000 1997; 14: 12-32.

3) Aldana L, Marker VA, Kolstad R, Iacopino AM. Effects of Candida treatment regimens on the physical properties of denture resins. Int J Prosthodont 1994; 7: 473-478.

4) Kuroki K, Hayashi T, Sato K, Asai T, Okano M, Kominami Y, Takahashi Y, Kawai T. Effect of self-cured acrylic resin added with an inorganic antibacterial agent on Streptococcus mutans. Dent Mater J 2010; 29: 277-285.

5) Ochi M, Chikazawa K, Hirose Y, Kubo Y, Sakaguchi K. Antimicrobial activity of synthetic resin monomer containing quaternary ammonium. J Jpn Soc Dent Prod 2000; 14: 2126.

6) Imazato S, Imai T, Russell RRB, Torii M, Ebisu S. Antibacterial activity of cured dental resin incorporating the antibacterial monomer MDPB and an adhesion-promoting monomer. J Biomed Mater Res 1998; 39: 511-515.

7) Kurata S, Umemoto K, Kumada H, Umemoto T, Kanazawa A, Ikeda T, Endo T. Study on antimicrobial dental resin using a polymeric phosphonium salt. J J Dent Mater 1997; 16 (Special Issue 29): 91.

8) Teraoka F, Takahashi J. Antibacterial activity of bamboo extract and its application in clinical dentistry. J J Dent Mater 1995; 14: 219-224.

9) Hotta M, Sekine I. Silver release from light-cured composite resin type temporary filling materials containing antibacterial filler $\left(\right.$ Novaron $\left.^{\circledR}\right)$. Jpn J Conserv Dent 1997; 40: 1004-1007.

10) Nakanoda S, Nikawa H, Hamada T, Yamamoto T, Nakamoto $\mathrm{K}$. The material and antifungal properties of antibiotic zeolite incorporated acrylic resin. J Jpn Prosthodont Soc 
1995; 39: 919-926.

11) Ohashi S, Yamamoto K. Antibacterial activity of Ag-silica glass as filler containing silver particles. J J Dent Mater 1997; 16: 241-248.

12) Yoshida T, Okamura H, Hasegawa M. Antibacterial effect, water absorption, solubility and transverse deflection of silver powder added to denture base resins. J J Dent Mater 1997; 16: 61-72.

13) Tanaka T, Mizukawa K, Shida K, Kobayashi T, Mega J. Application of silver-inorganic antimicrobial reagent for dental materials. J Jpn Prosthodont Soc 2000; 44: 651-657.

14) Li Y, Saito T, Gomyo S, Yoshida T, Sekine I. Evaluation of antibacterial activity of apical barrier material containing

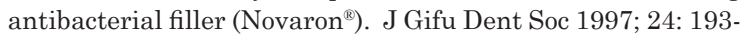
197.

15) Kobayashi T. Application of silver-inorganic antimicrobial reagent (NOVARON AG300) for acrylic resin —Antifungal action against Candida albicans. Nihon Univ J Oral Sci 1997; 23: 285-294.

16) Yamamoto $\mathrm{K}$, Ohashi S, Aono M, Kokubo T, Yamada I, Yamauchi J. Antibacterial activity of silver ions implanted in $\mathrm{SiO}_{2}$ filler on oral streptococci. Dent Mater 1996; 12: 227229.

17) Tamai K, Kawate K, Kawahara I, Takakura Y, Sakaki K. Inorganic antimicrobial coating for titanium alloy and its effect on bacteria. J Orthop Sci 2009; 14: 204-209.

18) Hotta M, Nakajima H, Yamamoto K, Aono M. Antibacterial temporary filling materials: the effect of adding various ratios of Ag-Zn-Zeolite. J Oral Rehabil 1998; 25: 485-489.

19) Tanimura Y, Watari F, Uo M, Totsuka Y. Visible light responsibility of titanium dioxide photocatalyst by metal ion decoration and basic research into dental application. $\mathrm{J} J$ Dent Mater 2002; 21: 342-350.

20) Kumagai $T$, Shinozaki $Y$. New surface treatment for polymer of self-curing resin. J Dent Res 2007; Special issue A: 86.

21) Kolenbrander PE, Palmer RJ Jr, Periasamy S, Jakubovics NS. Oral multispecies biofilm development and the key role of cell-cell distance. Nat Rev Microbiol 2010; 8: 471-480.

22) Berger TJ, Spadaro JA, Chapin SE, Becker RO. Electrically generated silver ions: quantitative effects on bacterial and mammalian cells. Antimicrob Agents Chemother 1976; 9: 357-358

23) Uchida M, Yamamoto T, Taniguchi A, Nakata S, Nakagawa Z. Reaction of silver ions and some amino acids. J Antibact Antifung Agents 2003; 31: 695-704.

24) Kourai H, Manabe Y, Yamada T. Mode of bactericidal action of zirconium phosphate ceramics containing silver ions in crystal structure. J Antibact Antifung Agents 1994; 22: 595602 . 